\title{
A Study on Tea Culture Tourism Development in Jiangxi Province
}

\section{XIONG Wenping}

(Nanchang Normal University, Nanchang, Jiangxi Province, China)

\author{
Key Words: Jiangxi, Tea Culture, Tourism, Development
}

Abstract: Based on the advantages of tea culture tourism development in Jiangxi, the strategies of tourism development for Jiangxi tea culture have been proposed in this Paper.

Tea culture tourism, a tourism mode, combines harmoniously tea resources and tourism, which integrates the ecological environment of tea plantations, tea production, the development of tea products and the connotations of tea culture. On the basis of tea area production in the beautiful landscape and picturesque scenery, relying on the variety of the natural landscape and particular historical and cultural landscape, it is a new type of tourism product covering various tourism functions, including sightseeing, experience, apprenticeship, entertainment, commercial trading, vacation and leisure, with colorful folk-custom activities connotative in tea culture. ${ }^{[1]}$

Jiangxi province is located in the southeastern China, the middle and lower reaches of the Yangtze River and called the "Land of Fish and Rice" in the southern regions of the Yangtze River. There are many rivers and lakes within the picturesque scenery and beautiful ecological environment. It has abundant tourism resources with several famous mountains, including the Sanqing Mountain, Jinggang Mountain and Lushan Mountain. Jiangxi has long enjoyed the laudatory title of "the place full of nature's treasures and outstanding people". The cultural heritage in Jiangxi is profound with a long history of tea plantation and production and the tea connotation is quite rich, which has made it the preponderant resource for the development of tea culture tourism.

For the tea culture tourism in Jiangxi, we need to create the cultural products and brands with regional characteristics of Jiangxi and promote the regional culture to be consistently developed with other industries such as tourism. Relying on the unique advantage of "Trademark of Origin" and "Geographical Indication" of Jiangxi province, we will endeavor to make it the characterized tea culture tourism industry base in China. Developing the integration of tea industry and cultural tourism industry as well as of the strategies for tea culture tourism development plays a positive role in tea industry upgrade and the tea culture tourism industry development in Jiangxi. For this purpose, on the basis of the detailed investigations to Jiangxi tea culture tourism, the author is discussing preliminarily the development of tea cultural tourism expecting that it will have some enlightenment for Jiangxi province and the regions which intend to develop such tourism project.

\section{Advantages of Tea Culture Tourism Development in Jiangxi}

\section{Resource Advantages}

Long History of Tea Culture

Jiangxi has a long history of tea producing. Its tea plantation and production can be traced back to the Eastern Han Dynasty. Since ancient times, Jiangxi has been one of the main provinces for tea 
production. Having developed to Tang Dynasty, the tea production in Jiangxi had been developed unprecedentedly fast and Jiangxi has become one of the seven tea production provinces then, especially in Fuliang and Wuyuan areas. They were not only the famous tea production areas, but also the important distributing centers of tea trading in China. This could be proved from the poem composed by the great poet, Bai Juyi in Tang Dynasty, that "Profit is what matters in the merchant's mind. Last month he went to Fuliang to purchase tea". Having developed to Song Dynasty, the tea production in Jiangxi had stepped into a fast development period with not only large quantity, but also superior quality.

\section{Rich Connotation}

Jiangxi is one of the main tea production provinces in China. During the long development history of tea industry, human intelligence and creativity has integrated into the tea and people has endowed tea with cultural characteristics, which is the most basic content of the tea culture in Jiangxi. With the development and progress of the society in Jiangxi, the splendid tea culture with regional characteristics in Jiangxi has been gradually formed, involving a wide range, including tea monographs, tea and poetry, tea and song and dance, tea and novels, tea and arts, tea stories, tea custom, tea ceremony, tea houses, tea snacks and treatment, tea exhibition and tea tourism.

The ceramic tea sets made in Jiangxi are so exquisite with large amount. Jingdezhen Kiln, Qilizhen Kiln in Ganzhou, Hongzhou Kiln in Fengcheng and Jizhou Kiln in Ji'an are all well-known porcelain kilns both at home and abroad. Having produced a large number of fine tea sets, especially Jingdezhen, has a long history of porcelain making with extremely high aesthetic value, strong ethnic style and Chinese manner ${ }^{[2]}$.

The Tea-picking Opera in Jiangxi has distinctive characteristics. It first appeared in Jiulongshan tea area in Anyuan county of the southern part of Jiangxi province (Gannan), and now has been developed into various local Tea-picking Operas with different characteristics, including Gannan Tea-picking Opera, Nanchang Tea-picking Opera, Fuzhou Tea-picking Opera. Among them, Ganan Tea-picking Opera has already been listed in the National Non-material Cultural Heritage List.

The well-developed tea activities in Jiangxi have also bred the tea songs and promoted their prevalence and development. "Comrades, please have a cup of tea!" This "Tea Invitation Song" with Jiangxi characteristic has prevailed in China and been popular among the masses of people. The traditional elements in the tea song of Jiangxi have been retained into the contemporary music and become the treasury of Jiangxi and Chinese culture.

The tea ceremony in Jiangxi started early in China with relatively great influence. The professional tea ceremony team had been established early in Jiangxi and had great influence both at home and abroad. Some tea ceremony teams had walked out of Jiangxi for a performance tour around China, which have even been invited to perform around world, enjoying high reputation both at home and abroad.

\section{Geographical Advantages}

Jiangxi is located in the middle reaches of the Yangtze River with the strategic position of "linking the east to the west and connecting the south with the north". It connects the Yangtze River Delta and the Pearl River Delta, which is beneficial to strengthen the lateral economic ties among these regions and promote the economic development. Jiangxi has obvious regional advantages and has been listed as the national strategies such as the Poyang Lake Ecological and Economic Development Zone, Cross-Strait Economic Development Zone, Rejuvenation and Development of Gannan and Other Central Soviet Areas and Urban Agglomerations along the Middle Reaches of the 
Yangtze River.

There are numerous well-known teas in Jiangxi, such as Lushan Clouds-Mist Green Tea, Jinggang Green Tea, Wuyuan Green Tea and Suichuan Gougunao Tea, distributed in the key tea production counties, including Wuyuan, Fuliang, Xiushui, Lushan, Jing'an, Zixi, Suichuan, Shangyou, Chongyi, Yudu and Ningdu. Among them, Lushan Clouds-Mist Green Tea, Jinggang Green Tea, Wuyuan Green Tea and Zixi White Tea are all within the range of scenic spots. The traffic is convenient: public transport lines inter-connect internally and the distances between the scenic spots are close; outside of these scenic spots, there are highways of Nanchang-Jiujiang, Jiujiang-Jingdezhen, Jiangxi-Guangdong, Liyuan-Wenjiazhen, Jingdezhen-Wuyuan-Huangshan, as well as the railways of Beijing-Kowloon, Xiangtang-Putian, Zhejiang-Jiangxi, Anhui-Jiangxi, Yingtan-Xiamen, Wuhan-Jiujiang, and Nanchang Changbei International Airport. They link with the surrounding counties and cities, and connect the surrounding provinces including Zhejiang, Fujian, Guangdong and Hubei. Many tea scenic spots lie on the golden tourism lines of the famous tourist attractions in Lushan, Jinggangshan, Wuyuan and Jingdezhen. Therefore, the tea culture tourism resources in Jiangxi have both predominant geographical advantages and well-known surrounding tourism resources, which have provided excellent conditions for the development of tea culture tourism.

\section{Market Advantages}

Generally, there are dense cities and relatively large population around the tea scenic spots in Jiangxi. Further, the surrounding cities such as Nanchang, Jiujiang, Jingdezhen and Ganzhou, have strong economic foundation and favorable open environment. The tourism demand is increasing vigorously.

Along with the successive maturity of the surrounding tourist attractions, while there are less attractive places in the urban areas, the tourists around the tea scenic spots, especially the urban residents, yearn for the countryside scenery and strongly expect better tourism products and alternatives. Therefore, relying on the surrounding large and middle cities will definitely make tea culture tourism in Jiangxi the main leisure, entertainment, shopping and sightseeing place in the region. To rely on the complementary advantages between the scenic spots and the surrounding tourist attractions and develop the tourist products can meet various demands of the tourists. It will be much easier for a success to have joint development with the aid of the tourism market which has already been formed in the scenic spots such as Lushan, Jinggangshan, Wuyuan and Jingdezhen.

\section{Strategies for Tea Culture Tourism Development in Jiangxi}

\section{Overall Planning and Rational Distribution}

The tea culture tourism involves three industries and many governmental departments. It has the dispersibility which is the specific characteristic that the trans-industrial departments have. In order to develop the tea culture tourism, we should aim at the industrial dispersibility and give full play to the regional public management function of the government and its leading coordinating role among the departments, as well as make good integration of various resources. The government should take the lead to formulate the regional tea culture tourism development strategy, implement the development of tea culture plan and strategy and supervise its implementation.

During the overall planning, each subsystem including Jiangxi tea culture tourism resources, tourism products, tourism basic facilities and tourism management should be scientifically and comprehensively planned; the measures should be adjusted according to the local conditions, such as the local tourism resources, tourism regional transportation conditions, social economic and 
cultural development, tourism market demand and regional features, to propose the blueprint for orderly development and construction. To achieve the anticipated goal, the plan for Jiangxi tea culture tourism should follow the principles of combining the cultural and historical traditions with time innovations as well as the construction and development of tourism sites, tea production and cultural inheritance with protection. The layout of Jiangxi tea culture tourism plan should firstly combine the local resource features and develop the projects with local characteristics; secondly, integrate local tourism resources to make the tourism products more plentiful and distinctive; lastly, it should cooperate with the adjacent tourism areas (points) to form concentrated attractions, realize mutual compensation of advantages and take the advantage of community superiority so as to attract more tourists with various interests.

\section{Strengthen the Construction of Jiangxi Tea Culture Tourism and Leisure Zones}

Strengthen the construction of the tea culture tourism zones and integrate the local regional culture with tea culture as well as the natural view with cultural customs to develop the tea culture tourism project with regional characteristics. In recent years, high class tea culture tourist resorts and attractions have come into being, such as the Yannanfei (Goose Flying South) in Meizhou, Guangdong province, which has turned the bare lands into a newly developing tourist attraction of high class integrating agricultural production, tourism and vacation entertainment. While in Jiangxi, Lushan Clouds-Mist green tea has been combined with Lushan Mountain scenery and Poyang Lake landscape. The Chinese Tea Museum in Hangzhou, Zhejiang province, the Tenfu Tea Museum and Stone Sculpture Garden in Zhangpu, Fujian province, the Tea Garden in Yingde, Guangdong province and the Tea Garden in the World Expo in Kunming are all tea culture tourism zones with distinctive characteristics. ${ }^{[3]}$ The construction of famous tea bases, the renovation of the cultural heritage and the creation of tourism environment are the three key points of the construction of tea culture tourism zones. Only these three key points being well accomplished can we attract numerous tourists especially the tea lovers to go sightseeing, entertaining and vacationing in the mountain areas. This will promote the economic social development there and contribute to the comprehensive construction of a well-off society. ${ }^{[4]}$ We should make great effort to strengthen the construction of tea culture tourism zones and make the tea culture tourism zones the tea culture tourist attractions and resorts combining sightseeing, leisure and vacation into one.

\section{Strengthen the Development and Brand Building of Jiangxi Tea Culture Tourism Productions}

There are six parts of tourism as food, accommodation, transportation, sightseeing, shopping and entertainment, among which food, drink and shopping are the important parts. Tea has become the tourism consumer goods and gift that the tourists regard important. Jiangxi has rich tea resources. Besides the teas with regional characteristics (such as Lushan Clouds-Mist green tea, Wuyuan green tea, Suichuan Gougunao tea and Fuyaoxianzhi etc.), the tourist goods with distinctive features should be developed with local cultural characteristics, so as to win popularity among the tourists. In the narrow sense, the tea products refer to the teas of various brands, while in a broad sense, they refer to the tourist goods with tea as the leading product, covering every aspect of tea culture, including tea sets, tea snacks, tea drawing, tea calligraphy, tea handicrafts and tea tourism souvenir. ${ }^{[3]}$ Vigorously develop the tourist products, focusing on the creativity and strengthen the quality production and marketing of tourist goods, as well as vigorously cultivate tea culture tourist products brands; develop a number of memorable and attractive tourist goods with superior quality and exquisitely unique design to make the brands grow big and strong and form the brand economic effect of the tourist goods. 


\section{Tap Cultural Connotation and Develop Varieties of Tourism Products}

It plays an important role for the enhancement of competitiveness of the tourist sites to well plan the tourism products, avoiding similarity while seeking for uniqueness ${ }^{[5]}$. Tea culture tourism resources are distributed throughout Jiangxi, dispersible but relatively centralized. Therefore, we should pay attention to the integrated development of various cultural resources. For the flexible localized design, we could combine the regional features and cultures with various tea cultures in different parts of Jiangxi to realize the perfect combination between tea culture and tourism in Jiangxi, glowing with cultural splendor. For example, in the areas with strong Jiangxi cultural features and distinctive regional characteristics, we could develop different tourism products such as ceramics tea culture tour, the "Hakka Style" tea culture and art experience tour and revolutionary tea culture tour etc. So as to make the characteristic high quality tea culture tourism the most beautiful cultural identity and image card of the region, and form the competitive products with diversity in the market, as well as achieve the monopoly, stability and effectiveness of the project development.

Lay equal stress on both culture and interest. Therefore, we should develop more projects with equal importance to culture and interest, and attract the attendance of the tourists, so as to extend their stay ${ }^{[6]}$.

\section{Create Atmosphere and Build the Carrier of Tea Culture}

Prepare good festival activities and performance, transferring from static state to dynamic state. Demonstrate Jiangxi tea culture through a number of large festival activities with Jiangxi tea culture as the subject and local characteristic festival activities, and combine the tea ceremony performance, rural home inns, local characteristic dances with tea garden views and ecological tourist sites, so as to form the characteristic highlights and make tea culture dynamic.

Build the carrier of tea culture, from none to all. Actively cultivate the tourism operational type with more culture content, such as tea trading market, tea ceremony and diet market, tea processing technology show site, tea ceremony performance team, tea songs and dances performance theater, grand ethnic songs and dances special performance, folk national minority variety performance theater, tea culture museum and tea appreciation club etc. ${ }^{[7]}$ As for the urban construction, especially some key tea production counties and places where tea brands orient, put the tea culture sculptures at the exits of the airports and railway stations, on the city streets and squares with relatively high passenger flow, to create an atmosphere which is compatible with tea culture with relevant sounds and pictures, so as to let the tourists experience the feelings of the tea land.

\section{Conclusion}

This Paper aims at making the tea culture tourism the landmark tourism project in Jiangxi, and making Jiangxi the tea culture tourism destination with brand influence as well as providing ideas for creating and promoting regional leisure culture tourism image of Jiangxi. Meanwhile, the strategies proposed in this Paper and relevant discussions will be beneficial to the cultivation and development of Jiangxi tea culture tourism as a strategic emerging industry, and have important strategic significance to further comprehensively promote the regional tea industry competitiveness in Jiangxi as well as to improve the position of Jiangxi tea culture tourism industry both in China and the world. The study on this subject would also provide references for the decision-making of the government and the development of tea industries in other areas both at home and abroad. 


\section{References:}

[1] ZHU Haiyan, ZHU Weifan, LIU Rong, LIU Zhonghua, Research On the Anhua Black Tea Culture Tourism Resource and Development Mode, [J] Chinese Agricultural Science Bulletin, 2010, 26 (13):

[2] NING Xiaoju, LIU Rongqing, Analysis On the Development of Jiangxi Tea Culture Tourism, [J] Agricultural Archaeology, 2010. 2.

[3] XU Mingsheng, HE Zhenzhong, Discussion On Three Key Points of the Construction of Huzhou Tea Culture Tourism Zone from the Top of Dalan, Fuquan, Huading and Cangshan. [J] Agricultural Archaelolgy, 2005 (02)

[4] XU Zurong, Research On the Development of Hangzhou Tea Culture Tourism, [J] Journal of Zhejiang Shuren University, 2007. 7

[5] XIAO Xing, Tourism Planning Tutorial [M]. Guangzhou: South China University of Technology Press, 2005, 8:93.

[6] TAN Chengwen, YANG Kaizhong, PENG Zhaohui, Discussion on the Development of Ancient Culture Tourism Products--with Luoyang As An Example, [J] Human Geography, 2001, 4 [7] WEN Nanxun, Research on the Integrated Development of Tea Culture Tourism Products, Journal of Yunnan University of Finance and Economics, 2007, 4 